\title{
Characterization of human pancreatic orthotopic tumor xenografts suitable for drug screening
}

\author{
Sandra Pérez-Torras • Anna Vidal-Pla • Rosa Miquel - Vanessa Almendro • \\ Laureano Fernández-Cruz • Salvador Navarro • Joan Maurel • Neus Carbó • \\ Pere Gascón • Adela Mazo
}

Accepted: 1 May 2011

(C) International Society for Cellular Oncology 2011

\begin{abstract}
Background Efforts to identify novel therapeutic options for human pancreatic ductal adenocarcinoma (PDAC) have failed to result in a clear improvement in patient survival to date. Pancreatic cancer requires efficient therapies that must be designed and assayed in preclinical models with improved predictor ability. Among the available preclinical models, the orthotopic approach fits with this expectation, but its use is still occasional.

Methods An in vivo platform of 11 orthotopic tumor xenografts has been generated by direct implantation of fresh surgical material. In addition, a frozen tumorgraft bank has been created, ensuring future model recovery and tumor tissue availability.
\end{abstract}

Electronic supplementary material The online version of this article (doi:10.1007/s13402-011-0049-1) contains supplementary material, which is available to authorized users.

\footnotetext{
S. Pérez-Torras $\cdot$ A. Vidal-Pla $\cdot$ N. Carbó $\cdot$ A. Mazo Departament de Bioquímica i Biologia Molecular, Institut de Biomedicina, Universitat de Barcelona, Diagonal 645,

08028 Barcelona, Spain
}

\section{R. Miquel}

Serveis de Patologia, Hospital Clínic de Barcelona (HCB),

Barcelona, Spain

V. Almendro · J. Maurel • P. Gascón

Oncologia, Hospital Clínic de Barcelona (HCB),

Barcelona, Spain

L. Fernández-Cruz

Cirurgia, Hospital Clínic de Barcelona (HCB),

Barcelona, Spain

S. Navarro

Gastroenterologia, Hospital Clínic de Barcelona (HCB),

Barcelona, Spain
Results Tissue microarray studies allow showing a high degree of original histology preservation and maintenance of protein expression patterns through passages. The models display stable growth kinetics and characteristic metastatic behavior. Moreover, the molecular diversity may facilitate the identification of tumor subtypes and comparison of drug responses that complement or confirm information obtained with other preclinical models.

Conclusions This panel represents a useful preclinical tool for testing new agents and treatment protocols and for further exploration of the biological basis of drug responses.

Keywords Pancreatic cancer Xenograft - Orthotopic . Biomarker D Drug screening

S. Navarro · J. Maurel · P. Gascón Institut d'Investigació Biomèdica August Pí i Sunyer (IDIBAPS), Barcelona, Spain

S. Pérez-Torras $\cdot \mathrm{S}$. Navarro $\cdot$ J. Maurel Centro de Investigación en Red de Enfermedades Hepáticas y Digestivas (Ciberehd),

Barcelona, Spain

P. Gascón

Red Temática de Investigación Cooperativa en Cáncer (RTICC), Barcelona, Spain

A. Mazo ( $\square)$

Departament de Bioquímica i Biología Molecular,

Facultat de Biologia, Universitat de Barcelona,

Diagonal 645,

08028 Barcelona, Spain

e-mail: amazo@ub.edu 


\section{Introduction}

Pancreatic adenocarcinoma is one of the most lethal cancers, owing to high dissemination at early stages, together with poor response to both radio- and chemotherapy [1]. To date, limited improvement in survival and in quality of life has been achieved with gemcitabine, the current standard treatment for pancreatic cancer [2]. Prognosis is still very poor with a 5 year-median survival of $1-4 \%$ and a median post-diagnosis survival period of only 4-6 months [3]. Despite significant efforts, there is an urgent need to develop new therapies to improve patient prognosis.

Until now, therapies exclusively addressed against a single molecular target have been inefficient, probably due to the frequent redundant and aberrant signals in tumor cells. Thus, inhibition of multiple signaling pathways, redefinition of molecular and cellular targets, and combined strategies play a key role in the response to therapy. To this end, the identification of signature gene mutations and molecular alterations in pancreatic adenocarcinomas provides a useful framework to develop more effective treatments. The multifactorial origin of PDAC supports the use of combined strategies as the therapy of choice. However, effective development of these strategies is hampered by a lack of good preclinical models. Therefore, translational research in PDAC is restricted by the limited value of the current preclinical models as predictors of treatment responses in patients. The majority of these models consists of subcutaneous tumors derived from established human cell lines, an approach that poorly represents the molecular and cellular heterogeneity of human PDAC tumors, and are thus poor predictors of clinical therapy responses [4]. Various attempts have been made to overcome these problems, including subcutaneous implantation and propagation of intact human tumor fragments in nude mice $[5,6]$. This approach partially solves the deficiencies observed with injecting cell lines, since the human tumor structure is preserved. However, the differences in tumor microenvironment, vascularization and metastatic spread continue to be major limitations of these models.

The orthotopic model is the most appropriate example that fulfils these requirements. In such models, solid fragments are implanted in the same organ in which the primary tumors were developed. When fragments come directly from patient, these xenografts have been named tumorgrafts [7-9]. This constitutes an efficient method to perpetuate these tumors, not only for treatment outcome analysis, but also for unlimited availability of tumor tissue. Implantation of histologically intact tumoral tissue may permit the establishment of intra- and intercellular interactions necessary for maintaining vascularized and viable tumors with spontaneous metastatic capacity, faithfully reproducing the original dissemination patterns. Interestingly, cryopreserved tissue has also been implanted with similar success rates as those from fresh tissue, facilitating the establishment of preclinical models from human samples [10] and the performance of different treatment assays at any time. Recently, an alternative method has been described in which a pancreatic cell suspension from digested patient tumors is injected into the pancreas of the athymic mice [11]. While no ideal experimental models exist for pancreatic cancer, orthotopic tumorgrafts appears to offer the closest approach to pancreatic cancer clinical situations [12, 13]

In view of this situation, we have generated and characterized an in vivo platform of orthotopic PDAC tumor xenografts via direct implantation of fresh human tumor tissue into the pancreas of athymic mice. This platform is representative of human pancreatic cancer, and constitutes a feasible, continual and improved in vivo approach to identify frequent molecular patterns and define and assess tailored combination treatments. Moreover, the platform offers a good possibility of considering the essential aspects of pancreatic cancer biology, such as microenvironment, cellular and molecular heterogeneity of tumors, and preservation of metastatic routes from a global viewpoint. Our final aim was to contribute to the improvement of human pancreatic cancer prognosis by better predicting the capacity of patient responses to new therapeutic agents.

\section{Materials and methods}

\subsection{Patient selection}

Fifteen patients subjected to surgical resection at the Hospital Clínic de Barcelona (HCB) were enrolled for this project over a 14-month period. All patients were staged using spiral CT and endoscopic ultrasound. Fourteen patients manifested with jaundice and one with weight loss. Fourteen patients were initially considered for surgical resection (no major vascular invasion or metastatic spread), and one patient (CP14) with locally advanced disease (invasion of the mesenteric artery, determined by $\mathrm{CT}$ ) was treated with chemoradiotherapy before surgery. All tumors were located at the head of the pancreas. Fourteen tumors were subjected to cephalic duodenopancreatectomy, and one to total pancreatectomy. The time from surgery to end of follow-up was 288 days (median, 185 days; range, $16-735$ days).

\subsection{Sample processing and model establishment}

\subsubsection{Primary human pancreatic cancer specimens}

Specimens were received immediately after surgery, and routinely processed at the Pathology Service. In each case, 
frozen sections of the pancreatic resection margin were obtained prior to obtaining fresh tissue from the tumor mass and normal pancreatic parenchyma and evaluated by frozen sections. Resection margins were negative in all cases. A tumor sample of approximately $0.5 \mathrm{cc}$ (see Supplemental 1) was placed in sterile DMEM/F-12 (Invitrogen) supplemented with antibiotics and antifungicidal agents, and transported to the animal facilities for rapid and direct xenografting into the pancreas of athymic nu/nu nude mice (Harlan Laboratories). In addition, fresh tissue samples from tumors and normal tissues were obtained, embedded in OCT, immediately frozen in isopentane, and stored at $-80^{\circ} \mathrm{C}$. Tumor samples included mirror areas of the site from which frozen tissue was obtained to evaluate tissue quality. Tissue samples for paraffin embedding for diagnostic purposes were obtained using standard routine protocols.

\subsubsection{Orthotopic model establishment}

In all cases, care was taken to minimize lap time, which oscillated between 2 and $4 \mathrm{~h}$, between obtaining surgical sections and fragment xenografting. Selected tumor fragments were split into $10 \mathrm{mg}$ pieces. Each of these pieces was implanted in four to five athimic mice. Animals were anesthetized with a ketamine/xylazine mixture i.p. (3:1), and a $3 \mathrm{~mm}$ left subcostal laparatomy performed. Spleen and pancreas were exposed, and the tumor piece was implanted in the pancreas with a vicryl suture. Organs were returned to the peritoneum, and the abdominal wall and skin sealed with a surgical staple. Animals were kept under observation until recovery from anesthesia. Surgical intervention survival was 100\%. Animal weights and physical conditions were monitored weekly, and tumor growth was followed by abdominal palpation. When the tumor reached the appropriate volume, euthanasia was performed and plasma from arterial blood was obtained. The primary tumor was removed and partly used to produce new orthotopic tumorgrafts in nude mice to perpetuate tumoral material. All animal work was performed in compliance with the guidelines and approval of the Institutional Animal Care Committee.

\subsubsection{Tumor model sampling and data processing}

Collected tumors were weighed and divided into representative fragments. Fragments were stored at $-80^{\circ} \mathrm{C}$ for western blot and sequencing analyses, cryopreserved and stored at $-196^{\circ} \mathrm{C}$ for future re-implantation, fixed in $10 \%$ formalin for paraffin embedding or embedded in OCT for immunohistochemical analysis. In some cases, disaggregated tumor material was plated on culture dishes for cell line generation. Dissemination patterns, metastatic incidence, animal weights and tumor growth rate and incidence were recorded in a database file (Microsoft Access ${ }^{\circledR}$ ).

\subsubsection{Tissue Microarray (TMA)}

Tissue microarrays of the 15 cases were constructed following standard methodologies, as described previously [14]. A selection of the donor paraffin blocks in each case included tumoral and normal pancreatic tissue, previous revision and marking of the $\mathrm{H} \& \mathrm{E}$ sections from which carcinoma assessment was made. From selected H\&E areas of each block, $2 \mathrm{~mm}$ punches were obtained and placed in a receptor paraffin block. At least two mice per model were analyzed. Each tumor was sampled in triplicate to ensure the presence of neoplastic glands since a high desmoplastic component is usual in PDAC. Each microarray block contained a maximum of 54 cores. Additional TMA were constructed from paraffin blocks of tumors grown in mice.

\subsubsection{Histological analysis and immunohistochemistry}

Serial $3 \mu \mathrm{m}$ sections were obtained from each TMA block and dried at $37^{\circ} \mathrm{C}$ overnight, prior to $\mathrm{H} \& \mathrm{E}$ and immunohistochemical staining. For immunohistochemistry analysis, histological sections were deparaffinized and rehydrated. The primary antibodies used were anti-CK7 (1/600 pepsin, OV-TL 12/30, Dako), anti-CK20 (1/800 pepsin, Ks 20-8, Dako), anti-Ki67 (1/200 CBI, MIB-1, DakoCytomation), anti-MUC1 (1/50 EDTA CBI, NCL-MUC1, Novocastra), anti MUC2 (1/100 EBI, NCL-MUC2, Novocastra), antiMUC4 (a gift of C. de Bolos, IMIM, Barcelona; 1/16 EBI), and anti-MMP7 (1:1500, Clone 111433, R\&D Systems). Slides were incubated for $60 \mathrm{~min}$ with the primary antibody, and developed using the EnVision signal detection system (DakoCytomation). The internal controls included in the detection system kits were used as monitors of intensity for these markers. Expression of the markers, CK7, CK20, MUC1, MUC2, MUC4 and MMP7, was recorded as a percentage of positive neoplastic cells, and expressed as an intensity code.

\subsection{6 p53 and KRAS sequencing}

DNA was extracted from human tumors and pancreatic xenografts following standard protocols. Intronic primers were used to avoid the amplification of mouse DNA. Intronic K-ras primers (Fwd: 5'GGTGGAGTATTTGA TAGTGTA3'; Rv: 5'GGTCCTGCACCAGTAATATGC3') were employed to amplify exon 2 of the K-ras gene. The whole coding sequence of exons 4 to 9 of p53 was amplified using intronic human primers described elsewhere [8]. Annealing temperature, extension time and concentration of $\mathrm{MgCl}_{2}$ were optimized for each primer set. Products from the first round of amplification were purified, and the same primers used for fragment sequencing with BigDye ${ }^{\circledR}$ Terminator v3.1 Cycle Sequencing Kit 
(Applied Biosystems), following the manufacturer's instructions.

\subsection{Western blot analysis}

Frozen tumoral samples were homogenized in cold lysis buffer [10 mM Tris, pH 7.5, $400 \mathrm{mM} \mathrm{NaCl}, 1 \mathrm{mM}$ EDTA, $10 \%$ glycerol, $0.5 \%$ Igepal CA-630, $5 \mathrm{mM} \mathrm{NaF}, 1 \mathrm{mM}$ sodium orthovanadate, $1 \mathrm{mM}$ DTT and one protease inhibitor cocktail tablet (Roche, Mannheim, RFA) per $10 \mathrm{ml}$ of buffer], and incubated at $4^{\circ} \mathrm{C}$ under orbital agitation for $1 \mathrm{~h}$. Samples were centrifuged at $15,000 \times \mathrm{g}$ for $15 \mathrm{~min}$. The total protein level in each supernatant was determined with the Bradford assay (BioRad). Samples containing equal amounts of protein were mixed with loading buffer containing 5\% 2-mercaptoethanol, heated for 5 min at $100^{\circ} \mathrm{C}$, and loaded onto a $8-12 \%$ SDS-PAGE gel. Electrophoretic transfer onto nitrocellulose membranes (Schleicher \& Schuell, Dassel, Germany) was examined by immunoblotting with anti-p16 (Pharmingen, G175-405), anti-Smad4 (Santa Cruz Biotechnology, SC-7966), antiEGFR (Santa Cruz Biotechnology, SC-03), anti-Her-2 (Santa Cruz Biotechnology, SC-284), anti-Her-3 (Santa Cruz Biotechnology, SC-285), anti-Akt (Santa Cruz Biotechnology, SC-1618), anti-p-Akt (S473) (Cell Signaling), anti-ERK (Cell Signaling, 137F5) anti-p-ERK (T202/Y204)
(Cell Signaling), anti-beta chain-IGF-1R (Santa Cruz Biotechnology, SC-713) and anti-p-IRS-1 (Y612) (Invitrogen) antibodies, followed by detection with horseradish peroxidase (HRP)-conjugated anti-mouse, anti-rabbit and and anti-goat IgGs (DAKO Corp, Carpinteria, CA, USA) (secondary antibodies). The chemiluminescent signal was developed using the ECL detection system (Amersham, Arlington Heights, IL, USA).

\section{Results}

\subsection{Clinical features of patients}

Fifteen pancreatic adenocarcinoma specimens (CP1 to CP15) from cancer patients were obtained by surgical resection at the Hospital Clinic of Barcelona. The main tumor features are listed in Table 1. Seven patients were men and eight were women with a median age of 74 years (mean of 67.3, range, 44-84). Median baseline CA19.9 values prior to surgery were $799.5 \mathrm{U} / \mathrm{ml}$ (range, 5-3510). The sizes of tumors ranged from 20 to $60 \mathrm{~mm}$ (median, 30; mean, 32). One of the patients (CP14) received prior chemoradiotherapy so that tumor size could not be evaluated on a macroscopic background due to fibrous substitution of whole pancreatic tissue. Scattered groups of

Table 1 Comparative histopathological features of primary tumors and orthotopic models

\begin{tabular}{|c|c|c|c|c|c|}
\hline \multicolumn{3}{|c|}{ Primary Human Tumours } & \multicolumn{3}{|l|}{ Orthotopic Xenografts } \\
\hline Model & $\begin{array}{l}\text { Differentiation } \\
\text { degree }\end{array}$ & Histology pattern & Differentiation degree & Histology pattern & $\begin{array}{l}\text { Latency } \\
\text { (weeks) }\end{array}$ \\
\hline $\mathrm{CP} 1$ & $\begin{array}{l}\text { Moderately } \\
\text { differenciated }\end{array}$ & $\begin{array}{l}\text { Well defined glands. Cribiform pattern. } \\
\text { Cell clusters in mucin lakes }\end{array}$ & $\begin{array}{l}\text { Moderately } \\
\text { differenciated }\end{array}$ & $\begin{array}{l}\text { Well defined glands. Cribiform pattern. } \\
\text { Cell clusters in mucin lakes }\end{array}$ & 6.4 \\
\hline $\mathrm{CP} 2$ & Well differenciated & Well defined glands & $\begin{array}{l}\text { Well and moderately } \\
\text { differenciated }\end{array}$ & Well defined glands. Cribiform pattern & 4.2 \\
\hline $\mathrm{CP} 3$ & $\begin{array}{l}\text { Moderately } \\
\text { differenciated }\end{array}$ & $\begin{array}{l}\text { Well defined glands. Irregular glandular } \\
\text { pattern. Mucinous cystic duct dilatation }\end{array}$ & $\begin{array}{l}\text { Moderately } \\
\text { differenciated }\end{array}$ & $\begin{array}{l}\text { Well defined glands. Irregular } \\
\text { glandular pattern. Mucoproduction }\end{array}$ & 4.2 \\
\hline CP5 & $\begin{array}{l}\text { Moderately } \\
\text { differenciated }\end{array}$ & $\begin{array}{l}\text { Well defined glands. Cribiform and } \\
\text { glandular pattern }\end{array}$ & $\begin{array}{l}\text { Moderately } \\
\text { differenciated }\end{array}$ & Mucoproduction. Papillary pattern & 0.4 \\
\hline CP8 & $\begin{array}{l}\text { Moderately } \\
\text { differenciated }\end{array}$ & $\begin{array}{l}\text { Well defined glands. Focal glandular } \\
\text { complex and papillary patterns }\end{array}$ & $\begin{array}{l}\text { Moderately and focal } \\
\text { poorly } \\
\text { differenciated }\end{array}$ & $\begin{array}{l}\text { Well defined glands. Focal glandular } \\
\text { complex and papillary patterns }\end{array}$ & 36.4 \\
\hline CP9 & $\begin{array}{l}\text { Moderately } \\
\text { differenciated }\end{array}$ & $\begin{array}{l}\text { Well defined glands. Cribiform pattern. } \\
\text { Cell clusters in mucin lakes }\end{array}$ & $\begin{array}{l}\text { Moderately } \\
\text { differenciated }\end{array}$ & $\begin{array}{l}\text { Cribiform and papillary pattern. } \\
\text { Mucoproduction }\end{array}$ & 5.1 \\
\hline CP10 & Well differenciated & Well defined glands & $\begin{array}{l}\text { Well and moderately } \\
\text { differenciated }\end{array}$ & Well defined glands. Cribiform pattern & 15.4 \\
\hline CP11 & $\begin{array}{l}\text { Moderately and } \\
\text { poorly } \\
\text { differenciated }\end{array}$ & $\begin{array}{l}\text { Complex glandular pattern. } \\
\text { Mucoproduction. Papillary pattern }\end{array}$ & $\begin{array}{l}\text { Moderately } \\
\text { differenciated }\end{array}$ & $\begin{array}{l}\text { Complex glandular pattern. } \\
\text { Mucoproduction. Papillary pattern }\end{array}$ & 38.1 \\
\hline CP12 & $\begin{array}{l}\text { Moderately } \\
\text { differenciated }\end{array}$ & $\begin{array}{l}\text { Well defined glands. Irregular glandular } \\
\text { pattern }\end{array}$ & $\begin{array}{l}\text { Moderately } \\
\text { differenciated }\end{array}$ & $\begin{array}{l}\text { Well defined glands. Irregular } \\
\text { glandular pattern }\end{array}$ & 15.8 \\
\hline CP13 & $\begin{array}{l}\text { Moderately } \\
\text { differenciated }\end{array}$ & Well defined glands. Cribiform pattern & $\begin{array}{l}\text { Moderately } \\
\text { differenciated }\end{array}$ & $\begin{array}{l}\text { Well defined glands Irregular } \\
\text { glandular and cribiform patterns }\end{array}$ & 7.3 \\
\hline CP15 & $\begin{array}{l}\text { Moderately } \\
\text { differenciated }\end{array}$ & Irregular glandular pattern & $\begin{array}{l}\text { Moderately } \\
\text { differenciated }\end{array}$ & $\begin{array}{l}\text { Well defined glands. Irregular } \\
\text { glandular pattern }\end{array}$ & 17.5 \\
\hline
\end{tabular}


neoplastic cells were observed microscopically throughout the extensive fibrous stroma. Histologically, all the tumors were pancreatic ductal adenocarcinomas, most of which were moderately differentiated. Survival time after surgery varied widely among patients (6,5 to 78 weeks), and four (CP6, CP10, CP12, CP15) received adjuvant chemotherapy $(5 \mathrm{FU} / \mathrm{LV})$.

\subsection{Model generation}

Four to five tumor fragments were obtained from each specimen, and subsequently implanted in the pancreas of athymic mice to generate the corresponding xenograft tumors.

Eleven out of 14 primary human tumors were successfully propagated, and a comparative histopathological study between the patient's primary tumors and generated tumorgrafts performed (Table 1 and Supplemental 2). Tumor- grafts were perpetuated from 4 to 12 generations, depending on the model. They retained original morphology of the human primary tumor as presented in Fig. 1a, for the CP2 and CP15 models. Moreover, despite fibrosis decreases in murine models when compared with primary tumors, these tumorgrafts maintained their desmoplasia degree through generations (Fig. 1b). First-generation latency periods ranged from 0.5 (CP5) to 38 weeks (CP11), but shortening of this lag time until tumor onset was observed for most models with successive passages. Moreover, variations in the percentage of tumor engraftment showed clear improvement with passage. Tumor material from each generation was cryopreserved, thus ensuring model availability for future preclinical assays. Newly generated tumors were characterized in a similar manner to the original tumor and initial tumor xenografts. Growth rates were additionally evaluated. The cell proliferation marker Ki67 was used to define the proliferative
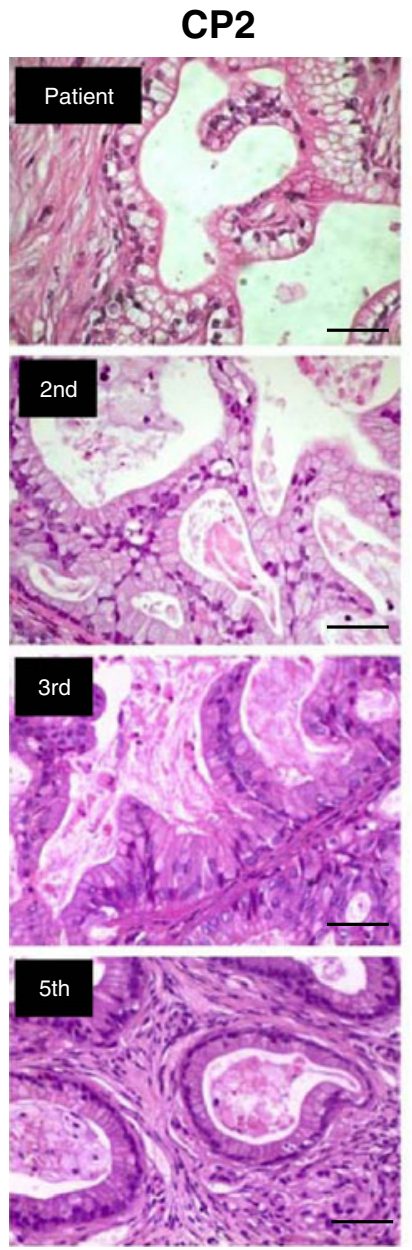

CP15
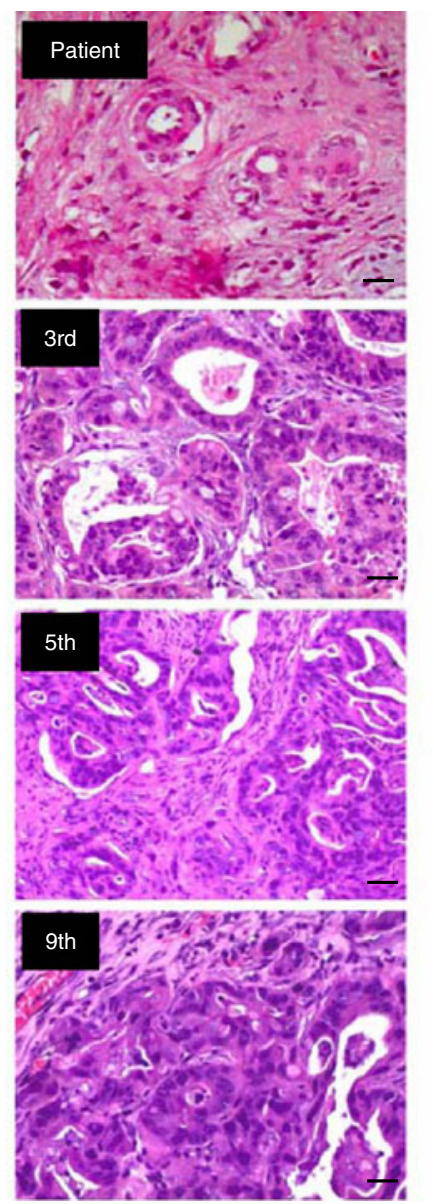

Fig. 1 Representative histological microscopic images of two primary human tumors (patient) and several generations of their corresponding tumorgrafts (H\&E and Masson trichrome staining) (bars: $100 \mu \mathrm{m})$. a) Characteristic well defined glandular pattern in CP2 primary tumor

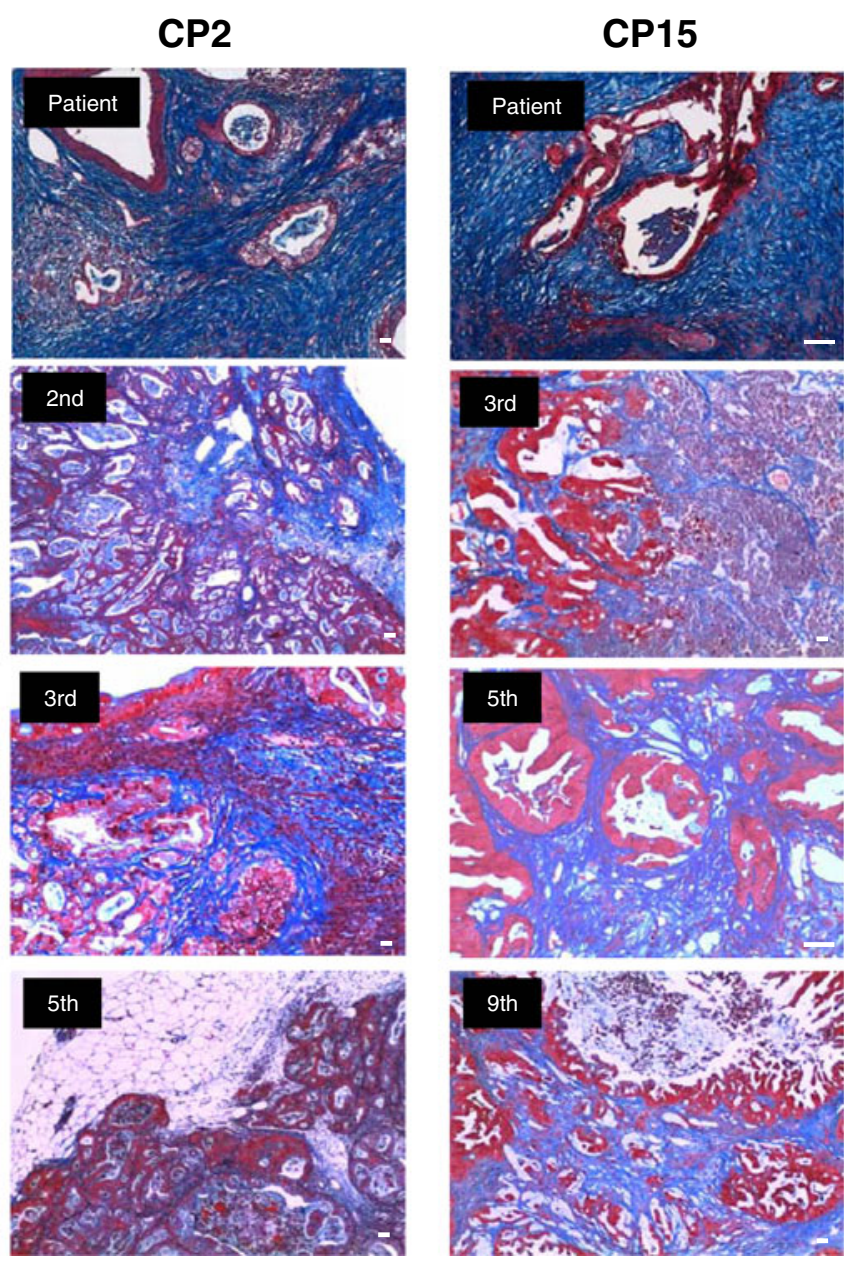

and different generations of tumorgrafts (left). Representative images of the CP15 primary tumor and several tumorgraft generations (right). b) Stromal fibrosis in primary tumors and different generations of $\mathrm{CP} 2$ (left) and CP15 models (right) 
rate of the tumors. The correlation was established by analysis of the percentages of expression of Ki67 in tumor samples from different generations. The Pearson correlation coefficient was in all cases higher than 0.95 (results not shown).

According to this, 3 out of 11 models were tagged as slow-growing, 5 as medium-growing, and 3 as fast-growing tumors.

\subsection{Dissemination patterns}

Tumor staging was assessed using the TNM classification system for malignant tumors. Lymph node and proximal organ/tissue invasion were monitored in patients displaying variable dissemination patterns (Table 2), with frequent perineural invasion, regional lymph node metastasis or direct tumor extension. Median nodal retrieval was 17 (mean, 20; range 10 to 32). Vascular invasion was detected in five cases, invasion of the duodenal wall in five cases, and in three cases, the intrapancreatic bile duct was also involved. Pancreatic anterior and/or posterior surfaces were additionally affected in most patients. Clear anterior and posterior pancreatic surfaces were recorded in only 2 cases, as evident from the lack of microscopically detectable neoplastic cells.

Some of implanted mice were used for tumor dissemination pattern assessment, and remained alive for at least 6 months until sacrifice for ethical reasons. In cases where information about local invasion and metastatic recurrence was available, the routes of invasion in mice were similar to those observed in patients. All mice displayed local dissemination, and hematological spreading was detected in almost all models, mainly to the liver, followed by lung (Table 2). Dissemination patterns were representative, model-specific and stable throughout passages.

\subsection{Epithelial markers}

The expression patterns of some common pancreatic epithelial markers (CK7, CK20, MUC1, MUC2 and MUC4) were comparatively assessed using immunohistochemistry on tissue microarrays in primary tumors and several generations of the different models (Fig. 2). These molecular markers exhibit a high degree of homology and stability, further supporting previous findings on histology preservation and stability of growth features of these models.

CK7 was expressed in all primary tumors and this expression was maintained or increased in xenografts. Significant CK20 expression was only detected in 2 cases, both corresponding to tumors with focal mucosecretion. Expression of both cytokeratins was concordant between primary tumors and their xenografts (Fig. 2A).

All primary tumors stained positive for apical membrane MUC1 in tumor glands and all xenografts, with the exception of $\mathrm{CP} 3$, were also positive, albeit with lower intensity. MUC2 expression was not observed in normal pancreatic tissue, and only one primary tumor (the focally

Table 2 Dissemination patterns in patients and tumorgrafts

\begin{tabular}{|c|c|c|c|c|c|c|c|c|}
\hline \multicolumn{6}{|c|}{ Primary human tumours } & \multirow[b]{2}{*}{$\begin{array}{l}\text { DFI } \\
\text { (months) }\end{array}$} & \multirow[b]{2}{*}{$\begin{array}{l}\text { Treatment at } \\
\text { recurrence }\end{array}$} & \multirow{2}{*}{$\frac{\text { Tumorgrafts }}{\text { Dissemination pattern }^{\mathrm{a}}}$} \\
\hline Model & $\begin{array}{l}\text { Tumour } \\
\text { staging }\end{array}$ & $\begin{array}{l}\text { Nodal } \\
\text { invasion }\end{array}$ & $\begin{array}{l}\text { Perineural } \\
\text { invasion }\end{array}$ & $\begin{array}{l}\text { Vascular } \\
\text { invasion }\end{array}$ & $\begin{array}{l}\text { Metastasic } \\
\text { Recurrence }\end{array}$ & & & \\
\hline CP1 & T3N0 & $0 / 32$ & 0 & 0 & LFU & LFU & UKN & Peritoneal, Mesenteric nodes, Liver, Lung \\
\hline $\mathrm{CP} 2$ & $\mathrm{~T} 3 \mathrm{~N} 1$ & $14 / 32$ & 1 & 1 & LFU & LFU & UKN & Peritoneal, Mesenteric nodes, Lung \\
\hline$C P 3$ & $\mathrm{~T} 3 \mathrm{~N} 1$ & $6 / 13$ & 1 & 1 & Lymph nodes & 2 & BSC & Peritoneal, Mesenteric nodes, Liver \\
\hline CP5 & $\mathrm{T} 3 \mathrm{~N} 1$ & $1 / 15$ & 1 & 0 & Local and peritoneal & 12 & GEM & Peritoneal, Mesenteric nodes, Liver, Lung \\
\hline CP8 & T2N0 & $0 / 10$ & 1 & 0 & $\begin{array}{l}\text { No evidence of } \\
\text { progression }\end{array}$ & +62 & NA & Peritoneal, Mesenteric nodes, Liver, Lung \\
\hline СР9 & T3N1 & $6 / 15$ & 0 & 1 & Local relapse & 6 & GEM & Peritoneal, Mesenteric nodes, Liver, Lung \\
\hline $\mathrm{CP} 10$ & $\mathrm{~T} 3 \mathrm{~N} 1$ & $4 / 18$ & 1 & 0 & LFU & LFU & UKN & Peritoneal and Mesenteric nodes \\
\hline CP11 & $\mathrm{T} 2 \mathrm{~N} 1$ & $2 / 15$ & 1 & 1 & Lymph nodes, Lung & 11 & $\begin{array}{l}\text { GEM-ERLO+/- } \\
\text { BEV }\end{array}$ & Peritoneal and Mesenteric nodes, Liver \\
\hline CP12 & T3N0 & $0 / 17$ & 0 & 0 & $\begin{array}{l}\text { No evidence of } \\
\text { progression }\end{array}$ & +59 & NA & Peritoneal \\
\hline CP13 & $\mathrm{T} 2 \mathrm{~N} 1$ & $2 / 21$ & 1 & 0 & LFU & LFU & UKN & Peritoneal, Mesenteric nodes, Liver \\
\hline CP15 & $\mathrm{T} 3 \mathrm{~N} 1$ & $15 / 28$ & 1 & 1 & $\begin{array}{l}\text { lymph nodes, } \\
\text { Liver, suprarenal }\end{array}$ & 9 & GEM-AXI & Peritoneal, Liver, Lung \\
\hline
\end{tabular}

$L F U$ lost of follow up; BSC Supportive care; NA not applicable; GEM gemcitabine; ERLO erlotinib; $A X I$ axitinib; $B E V$ bevacizumab; $U K N$ unknown

${ }^{\text {a }}$ Metastasic dissemination was evaluated at the sacrifice time and without removing primary tumors 
mucosecretor CP1) expressed high levels of MUC2 in the mucinous areas, with no expression in the usual adenocarcinoma areas. This pattern was maintained in xenografts (Fig. 2B).

MUC4 was faintly expressed in the Langerhans islets and tumor areas. Nine primary tumors stained positive for MUC4, with highly heterogeneous grading between cases. Two positive primary tumor-derived xenografts (CP2 and CP3) lost MUC4 expression, whereas 7 others retained MUC4 expression with patterns similar to those of primary tumors (Fig. 2B)

\subsection{Pancreatic cancer markers}

The gene status of $K$-Ras and p53 was determined by genomic DNA sequencing (Fig. 3A). The K-Ras gene was mutated at codon 12 in all the models. The majority $(80 \%)$ of the models bear a common second bp codon 12 mutation, specifically, G/A change $(50 \%)$ and G/T change (30\%), with the remaining $20 \%$ displaying mutations at the first bp (G/C change). Mutational analyses revealed that the p53 suppressor gene was altered in $60 \%$ of the models analyzed, with all the alterations located either at exon 5 or 8. Apart from $\mathrm{CP} 2$ and $\mathrm{CP} 8$, all frequently altered $p 53$ codons were point mutations. Expression levels of other key tumor suppressors in PDAC, such as p16 and DPC4, were analyzed using WB (Fig. 3B). p16 expression was only detected in CP2. DPC4 expression was clearly detected in CP5, CP11 and CP13, and weakly in CP9, $\mathrm{CP} 10$ and $\mathrm{CP} 12$.

3.6 Tyrosine Kinase Receptors (RTK) signaling and MMP-7

Comparative levels of EGFR, Her-2 and Her-3 ErbB family members and IGF-IR were analyzed using WB in second or

\section{A Primary tumors}
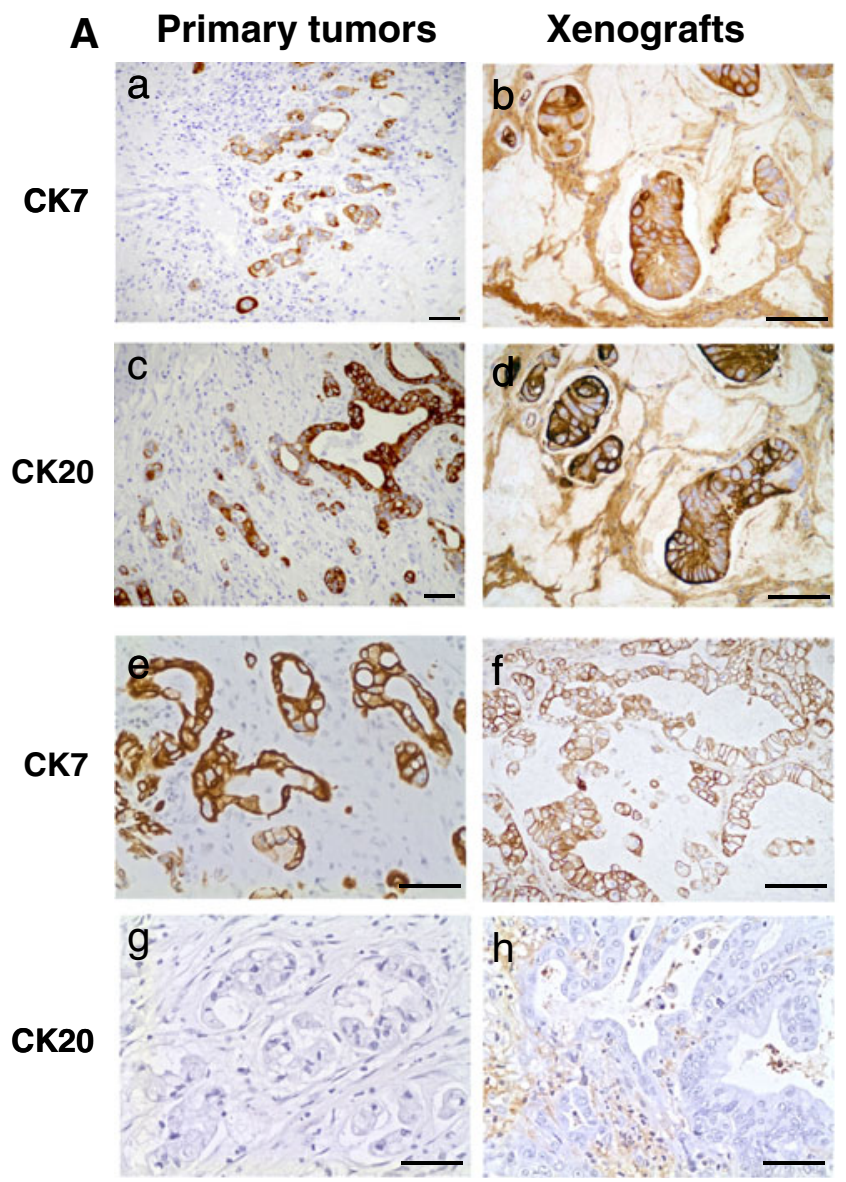

Fig. 2 Immunohistochemical analysis of cytokeratins (CK7 and CK20) and MUC proteins (MUC1, MUC2 and MUC4) using tissue microarray (bars:100 $\mu \mathrm{m}$ ). A) Comparative staining of CP1 primary tumor (a,c) and CP1 tumorgraft $(\mathbf{b}, \mathbf{d})$ shows expression of CK7 in the majority of the tumor glands, including the mucinous areas $(\mathbf{a}, \mathbf{b})$. Intense coexpression of CK20 in the same areas is observed (c,d); Comparative staining of $\mathrm{CP} 3$ primary tumor $(\mathbf{e}, \mathbf{g})$ and $\mathrm{CP} 3$ tumorgraft

\section{B Primary tumors Xenografts}
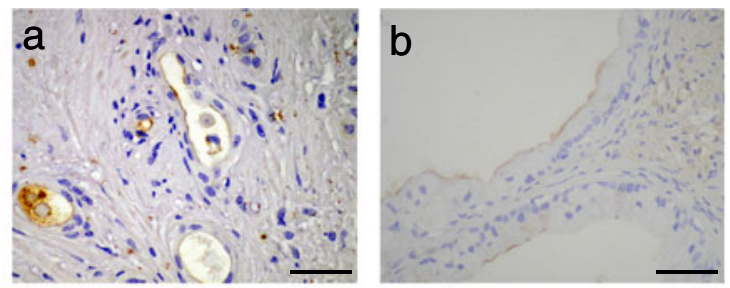

MUC1
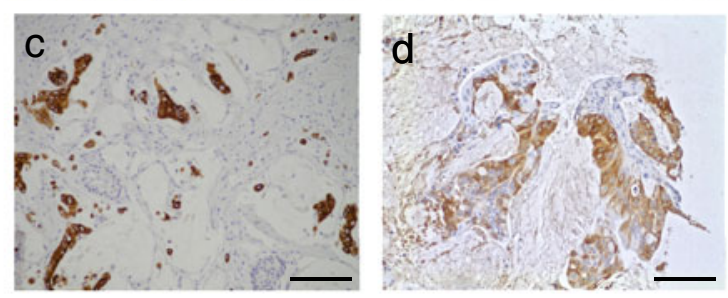

MUC2
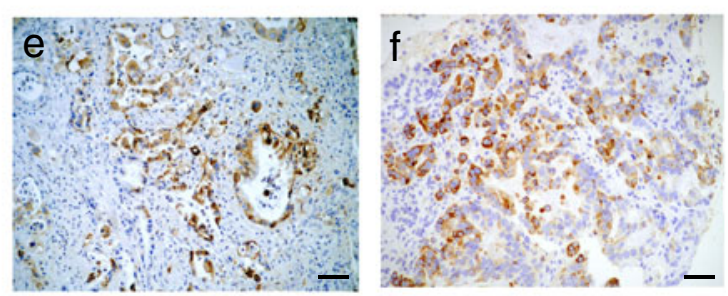

MUC4

(f,h) shows expression of CK7 in tumor glands (e and f) and absence of CK20, both in the primary tumor (g) and the tumorgraft (h). B) Characteristic apical immunostaining of MUC1 in the CP2 primary tumor (a) and the derived tumorgraft (b). Mucosecretory areas of CP1 tumor (c) or its corresponding tumorgraft (d) showing representative MUC2 intense cytoplasmic expression. Highly positive MUC4 in both, the CP9 primary tumor (e) and the derived tumorgraft (f) 
Fig. 3 Gene status and protein levels of pancreatic cancer markers. A) $K$-Ras and $p 53$ gene status. Exon 2 of $K$-Ras gen was sequenced and all the models showed different mutations in codon 12. Different alterations found in $p 53$ gene, all of them in exons 5 or 8. B) Expression levels of the tumor suppressors proteins p16 and DPC4 were assessed using WB in all the tumor models
A

\begin{tabular}{cc|c}
\hline Model & $\begin{array}{c}\text { p53 } \\
\text { exons 4 to 9 }\end{array}$ & $\begin{array}{c}\text { K-Ras } \\
\text { codon 12 mutation }\end{array}$ \\
\hline CP1 & wt & GGT $\rightarrow$ GAT \\
CP2 & 27 bp duplication exon 5 (codons 162-170) & GGT $\rightarrow$ CGT \\
CP3 & wt & GGT $\rightarrow$ GAT \\
CP8 & 10 bp deletion exon 5 (frameshift) & GGT $\rightarrow$ GAT \\
CP9 & Codon 163 exon 5 (Tyr $\rightarrow$ Cys) & GGT $\rightarrow$ GTT \\
CP10 & wt & GGT $\rightarrow$ GTT \\
CP11 & Codon 273 exon 8 (Arg $\rightarrow$ His) & GGT $\rightarrow$ GTT \\
CP12 & Codon 282 exon 8 (Arg $\rightarrow$ Trp) & GGT $\rightarrow$ GAT \\
CP13 & Codon 175 exon 5 (Arg $\rightarrow$ His) & GGT $\rightarrow$ CGT \\
CP15 & wt & GGT $\rightarrow$ GAT \\
\hline
\end{tabular}

B \begin{tabular}{|lllllllllll}
$\mathrm{CP} 1$ & $\mathrm{CP} 2$ & $\mathrm{CP} 3$ & $\mathrm{CP} 5$ & $\mathrm{CP} 8$ & $\mathrm{CP} 9$ & $\mathrm{CP} 10$ & $\mathrm{CP} 11$ & $\mathrm{CP} 12$ & $\mathrm{CP} 13$ & $\mathrm{CP} 15$ \\
\hline & & & & & & & & & \\
\hline
\end{tabular} third generations of all the tumor xenografts. Several phosphorylated downstream proteins were also analyzed, such as p-AKT (S473), p-ERK (Y204/T202) and p-IRS-1 (Y612). Different patterns have been obtained, ranging from a clear positivity in both, p-AKT and p-ERK, e.g. CP12 model, to undetectable levels, as in the CP15 model (Fig. 4). Additionally, given that MMP-7 has been recently involved in RTK transactivation, we checked for their expression in all tumor models. Considering as negative staining percentages up to $30 \%$ of the tumor, $64 \%$ of the models were positive for MMP-7 expression (Fig. 5).

\section{Discussion}

An ideal model for pancreatic cancer should provide researchers with relevant data to guide the design of clinical trials. Several preclinical pancreatic cancer models have
Fig. 4 Characterization of RTK signaling. Expression levels of ErbB family proteins (EGFR, Her-2, Her-3), IGF-IR and phosphorylated signaling proteins (p-AKT, p-ERK, and pIRS-I) were assessed using Western Blot in all the tumor models

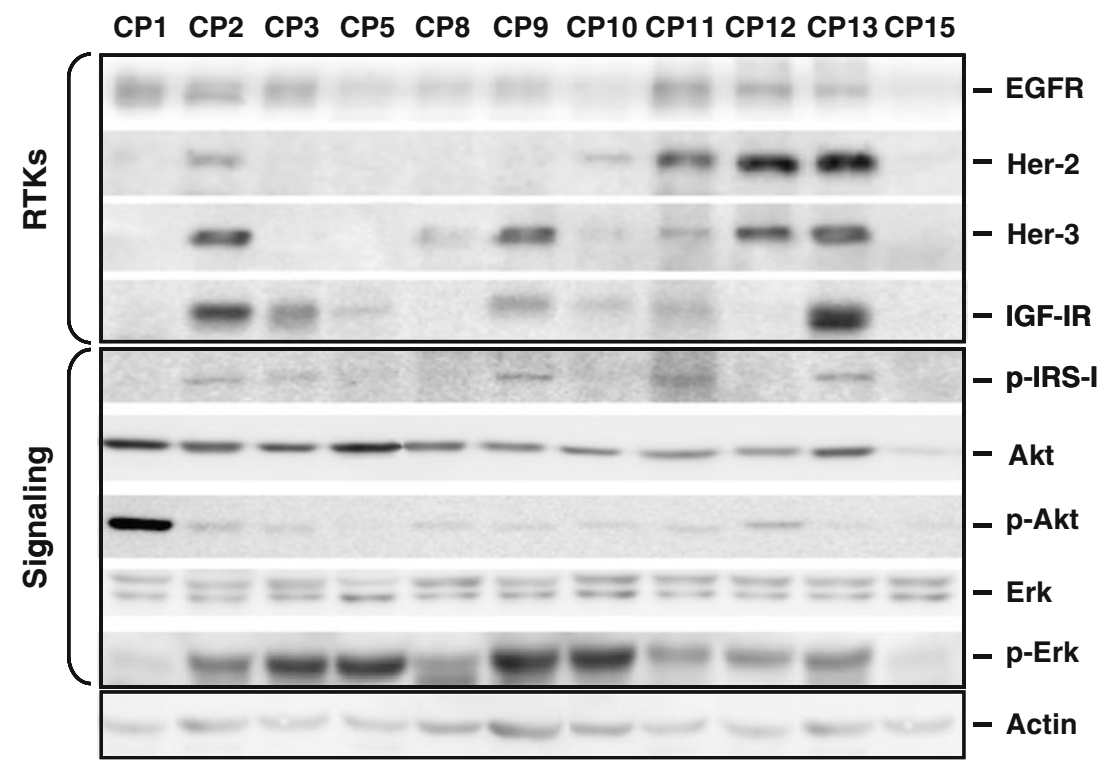


Fig. 5 Immunohistochemical analysis of MMP-7 expression. A) Representative MMP-7 staining of different tumor models. CP3 (totally negative); CP8 (20-30\% of positive cells); CP15 (positive) (bars:100 $\mu \mathrm{m}$ ). B) Summary of comparative MMP-7 expression values in primary tumors and tumorgrafts

\section{A}
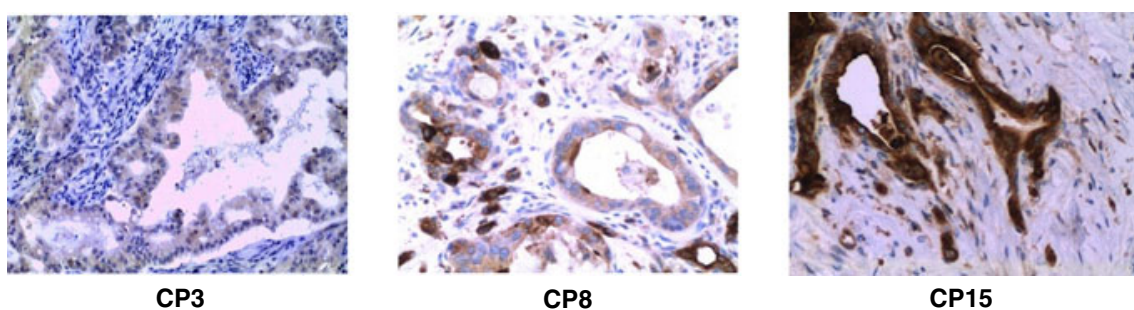

B

\begin{tabular}{lccl}
\hline Model & Primary tumors & Tumorgrafts & \multicolumn{1}{c}{ Comments } \\
\hline CP1 & $20 \%$ positive cells & $20 \%$ positive cells & only isolated positive cells \\
CP2 & $20 \%$ positive cells & $10 \%$ positive cells & only isolated positive cells \\
CP3 & negative & negative & \\
CP5 & positive & n.d. & $80-100 \%$ positive cells \\
& & & \\
CP8 & $30 \%$ positive cells & $10 \%-20 \%$ positive cells & \\
& & & \\
CP9 & positive & $10-20 \%$ positive cells & some areas (less than 20\%) totally negative \\
CP10 & positive & positive & $80-100 \%$ positive cells \\
CP11 & positive & $5 \%$ positive & tumor areas (10\%) weekly positive or negative \\
CP12 & positive & positive & $80-100 \%$ positive cells \\
CP13 & positive & positive & $80-100 \%$ positive cells \\
CP15 & positive & positive & $80-100 \%$ positive cells \\
\hline
\end{tabular}

been extensively used with this aim, each of which contributes essential information on pancreatic cancer biology and treatment responses. Effective preclinical models must take into account the heterogeneity of the disease to predict not only the overall antitumoral activity of a new drug but also the subsets of tumors in which they will be effective. A recent published Consensus Report of the NCI Clinical Trials Planning Meeting strongly recommends the development of preclinical tumor models that are better predictive of human pancreatic cancer. Furthermore, it indicates the potential of primary patient-derived tumor xenografts as a platform for drug screening, biomarker development, and to expand knowledge of the biology of pancreatic cancer [13].

In this work, we have built a direct pancreatic cancer orthotopic platform with an engraftment rate of 59\% in first passage, 76 rate in second page and $90 \%$ in the third generation passage. This platform has been generated with the aim of preclinical testing novel treatment modalities. In this approach, human primary tumors were allowed to form in mouse pancreatic tissue, and from the beginning, to progress in a proper microenvironment. Thus, tissue-specific interactions between tumor cells and the surrounding compartments, increasingly recognized as the major determinants of tumor phenotype, are maintained $[15,16]$. These models preserve the histological architecture between the original tumors and their tumorgrafts and throughout generations, an essential trait that is hardly recapitulated by other approaches such as those based on cells inoculation into the pancreas or by implantation of subcutaneous donor tumors [17-19]. Moreover, although fibrosis experimented a substantial decrease with respect to primary tumors, these tumorgrafts maintained a significant desmoplasia degree through generations Interestingly, transition zones between tumor, fibrotic tissue and normal pancreas can be observed (Supplemental 3). Besides, our orthotopic tumors spread using the clinically relevant routes of lymphatic and vascular metastasis and this dissemination patterns are stable and tumor-specific. All these traits are highly valuable for repetitive preclinical assay performance and treatment validation. 
Profiling of ductal differentiation markers, such as mucins and cytokeratins, may aid in tumor characterization and monitoring passage-derived deviations. Regarding to mucins, MUC1 and MUC4 seem to play a key role in the progression of the disease and have been proposed as markers of poor prognosis whereas MUC2 plays usually a tumor suppressor role and is rarely detectable in aggressive pancreatic tumors [20-23] .In our study, MUC1 and MUC4 were present in $100 \%$ and $80 \%$ tumors, respectively, whereas only $20 \%$ of primary tumors were positive for MUC2. With respect to cytokeratins, although the expression of a single $\mathrm{CK}$ is of little diagnostic value, the expression pattern of CK7/CK20 in epithelial tumors has been proposed as useful in distinguishing primary from metastatic carcinomas of varied origins [24, 25]. In our platform, ubiquitous CK7 expression is evident in all the tumors whereas CK20 is present in only $20 \%$ of the tumors. Globally, our data on these epithelial markers are consistent with their roles and incidence in pancreatic tumor development. Their expression patterns are concordant between tumorgrafts and primary tumors, highlighting again, the strength of this approach as a good representative platform for human pancreatic cancer disease.

Orthotopic implantation of histologically intact human carcinoma tissue offers the possibility of evaluating candidate-selective treatment modalities in resected cancer patients [4, 12, 26, 27]. Additionally, active forms of intracellular signaling proteins and/or stroma or vascularization regulators constitute key biomarkers of new targeted therapies to be tested in advanced PDAC [4-6].

In the last years, insulin-like growth factor-1 receptor (IGF-IR) has emerged as a potential target for antitumor therapies. In pancreatic cancer, a frequent overexpression of IGF-IR and its ligands has been reported [28, 29]. IGF-IR can potently contribute not only to the development of tumors but also to the resistance to therapy [30, 31]. In this sense, it has been recently reported that concomitant expression of MMP7 and activation of p-IGF-1R correlates with poor prognosis in colon cancer patients treated with inhibitors of EGFR [32]. From data obtained from RTK signaling and MMP7 expression in our models, they may be grouped in 3 patterns based on an EGFR and IGF-1R inhibition hypothesis driven efficacy. In this sense, $\mathrm{RTK}+$ / MMP7- tumors could be initially sensitive to combinations of EGFR and IGF-1R inhibitors although acquired resistance can emerge through HER-3 or HER-2 activation [33]. In contrast, RTK+/MMP7+ or RTK-/MMP7+ tumors would be intrinsically resistant to combinations of EGFR and IGF$1 \mathrm{R}$ inhibitors due to alternative IGF-1R-independent pathways regulated by MMP-7 [34] such as TRAIL [35, 36] or absence of target expression (RTK), respectively. It is remarkable that, considering our hypothesis-based of IGF$1 \mathrm{R}$ resistant pattern, only $36 \%$ of our models are expected to respond to combinations of gemcitabine plus erlotinib and IGF-1R inhibitors combined therapies, in accordance with recent data in early phase II clinical trials in PDAC $[13,37]$. An inherent limitation of our study is that this platform is derived from resected patients and then, only represents $20 \%$ of all patients with PDAC. We can not rule out that tumors obtained from metastatic PDAC patients would show different patterns, an aspect that should be evaluated in the future. In addition, other studies based on different hypothesis-driven, for instance, patterns based on hedgehog signaling [38], can complement optimal preclinical data in PDAC.

We conclude that the orthotopic tumor xenograft approach presented as a platform established from 11 patients facilitates progress in pancreatic cancer knowledge. Despite being slightly more complex to establish than other preclinical models, the global information provided by these models allows the detailed exploration of pancreatic genetics, biology and drug response in the whole animal context, thereby mimicking better than in other models the environment in which human disease occurs. Collectively, they constitute a useful preclinical platform for examining new agents and treatment protocols, as well as further exploring the biological basis of human pancreatic cancer and drug responses.

Acknowledgments This research was supported by Ministerio de Ciencia e Innovación, Grant BIO2005-08682-C03-03 and BIO200804692-C03-03 and Ministerio de Sanidad y Consumo, Grant 03/156. AVP has been FI fellow recipient.

We are very grateful to Raquel Longarón, Eva Fernández, and Ingrid Victoria for technical work in characterization of gene status, tissue microarrays and histochemistry/immunohistochemistry, respectively.

\section{References}

1. H.L. Kindler, Pancreatic cancer: an update. Curr. Oncol. Rep. 9, 170-176 (2007)

2. J.D. Berlin, P. Catalano, J.P. Thomas, J.W. Kugler, D.G. Haller, A. B. Benson 3rd, Phase III study of gemcitabine in combination with fluorouracil versus gemcitabine alone in patients with advanced pancreatic carcinoma: Eastern Cooperative Oncology Group Trial E2297. J. Clin. Oncol. 20, 3270-3275 (2002)

3. A. Jemal, R. Siegel, E. Ward, Y. Hao, J. Xu, T. Murray, M.J. Thun, Cancer statistics, 2008. CA Cancer J. Clin. 58, 71-96 (2008)

4. J.E. Talmadge, R.K. Singh, I.J. Fidler, A. Raz, Murine models to evaluate novel and conventional therapeutic strategies for cancer. Am. J. Pathol. 170, 793-804 (2007)

5. B. Rubio-Viqueira, A. Jimeno, G. Cusatis, X. Zhang, C. Iacobuzio-Donahue, C. Karikari, C. Shi, K. Danenberg, P.V. Danenberg, H. Kuramochi, K. Tanaka, S. Singh, H. SalimiMoosavi, N. Bouraoud, M.L. Amador, S. Altiok, P. Kulesza, C. Yeo, W. Messersmith, J. Eshleman, R.H. Hruban, A. Maitra, M. Hidalgo, An in vivo platform for translational drug development in pancreatic cancer. Clin. Cancer Res. 12, 4652-4661 (2006)

6. B. Rubio-Viqueira, M. Hidalgo, Direct in vivo xenograft tumor model for predicting chemotherapeutic drug response in cancer patients. Clin. Pharmacol. Ther. 85, 217-221 (2009) 
7. X. Fu, F. Guadagni, R.M. Hoffman, A metastatic nude-mouse model of human pancreatic cancer constructed orthotopically with histologically intact patient specimens. Proc. Natl Acad. Sci. U.S. A. 89, 5645-5649 (1992)

8. G. Capella, L. Farre, A. Villanueva, G. Reyes, C. Garcia, G. Tarafa, F. Lluis, Orthotopic models of human pancreatic cancer. Ann. NY Acad. Sci. 880, 103-109 (1999)

9. K. Garber, From human to mouse and back: 'tumorgraft' models surge in popularity. J. Natl. Cancer Inst. 101, 6-8 (2009)

10. C. Sorio, A. Bonora, S. Orlandini, P.S. Moore, P. Capelli, P. Cristofori, G. Dal Negro, P. Marchiori, G. Gaviraghi, M. Falconi, P. Pederzoli, G. Zamboni, A. Scarpa, Successful xenografting of cryopreserved primary pancreatic cancers. Virchows Arch. 438, 154-158 (2001)

11. M.P. Kim, D.B. Evans, H. Wang, J.L. Abbruzzese, J.B. Fleming, G.E. Gallick, Generation of orthotopic and heterotopic human pancreatic cancer xenografts in immunodeficient mice. Nat. Protoc. 4, 1670-1680 (2009)

12. R.M. Hoffman, Orthotopic metastatic mouse models for anticancer drug discovery and evaluation: a bridge to the clinic. Invest. New. Drugs. 17, 343-359 (1999)

13. P.A. Philip, M. Mooney, D. Jaffe, G. Eckhardt, M. Moore, N. Meropol, L. Emens, E. O'Reilly, M. Korc, L. Ellis, J. Benedetti, M. Rothenberg, C. Willett, M. Tempero, A. Lowy, J. Abbruzzese, D. Simeone, S. Hingorani, J. Berlin, J. Tepper, Consensus report of the national cancer institute clinical trials planning meeting on pancreas cancer treatment. J. Clin. Oncol. 27, 5660-5669 (2009)

14. J. Kononen, L. Bubendorf, A. Kallioniemi, M. Barlund, P. Schraml, S. Leighton, J. Torhorst, M.J. Mihatsch, G. Sauter, O. P. Kallioniemi, Tissue microarrays for high-throughput molecular profiling of tumor specimens. Nat. Med. 4, 844-847 (1998)

15. S. Kumar, V.M. Weaver, Mechanics, malignancy, and metastasis: the force journey of a tumor cell. Cancer Metastasis Rev. 28, 113127 (2009)

16. G.C. Chu, A.C. Kimmelman, A.F. Hezel, R.A. DePinho, Stromal biology of pancreatic cancer. J. Cell. Biochem. 101, 887-907 (2007)

17. A.L. Kung, Practices and pitfalls of mouse cancer models in drug discovery. Adv. Cancer Res. 96, 191-212 (2007)

18. H.G. Hotz, H.A. Reber, B. Hotz, T. Yu, T. Foitzik, H.J. Buhr, G. Cortina, O.J. Hines, An orthotopic nude mouse model for evaluating pathophysiology and therapy of pancreatic cancer. Pancreas. 26, e89-e98 (2003)

19. S. Marchan, S. Perez-Torras, A. Vidal, J. Adan, F. Mitjans, N. Carbo, A. Mazo, Dual effects of beta3 integrin subunit expression on human pancreatic cancer models. Anal. Cell Pathol/Cellular Oncology 33, 191-205 (2010)

20. M. Andrianifahanana, N. Moniaux, B.M. Schmied, J. Ringel, H. Friess, M.A. Hollingsworth, M.W. Buchler, J.P. Aubert, S.K. Batra, Mucin (MUC) gene expression in human pancreatic adenocarcinoma and chronic pancreatitis: a potential role of MUC4 as a tumor marker of diagnostic significance. Clin. Cancer Res. 7, 4033-4040 (2001)

21. K. Nagata, M. Horinouchi, M. Saitou, M. Higashi, M. Nomoto, M. Goto, S. Yonezawa, Mucin expression profile in pancreatic cancer and the precursor lesions. J. Hepatobiliary Pancreat Surg. 14, 243-254 (2007)

22. A.P. Singh, P. Chaturvedi, S.K. Batra, Emerging roles of MUC4 in cancer: a novel target for diagnosis and therapy. Cancer Res. 67, 433-436 (2007)

23. A. Westgaard, A.R. Schjolberg, M. Cvancarova, T.J. Eide, O.P. Clausen, I.P. Gladhaug, Differentiation markers in pancreatic head adenocarcinomas: MUC1 and MUC4 expression indicates poor prognosis in pancreatobiliary differentiated tumours. Histopathology. 54, 337-347 (2009)

24. S. Meer, M. Altini, CK $7+/$ CK20- immunoexpression profile is typical of salivary gland neoplasia. Histopathology. 51, 26-32 (2007)
25. F.H. Schmitz-Winnenthal, C. Volk, B. Helmke, S. Berger, U. Hinz, M. Koch, J. Weitz, J. Kleeff, H. Friess, M. Zoller, M.W. Buchler, K. Z'Graggen, Expression of cytokeratin-20 in pancreatic cancer: an indicator of poor outcome after R0 resection. Surgery. 139, 104-108 (2006)

26. M.C. Bibby, Orthotopic models of cancer for preclinical drug evaluation: advantages and disadvantages. Eur. J. Cancer 40, 852857 (2004)

27. H.H. Fiebig, A. Maier, A.M. Burger, Clonogenic assay with established human tumour xenografts: correlation of in vitro to in vivo activity as a basis for anticancer drug discovery. Eur. J. Cancer 40, 802-820 (2004)

28. E. Karna, A. Surazynski, K. Orlowski, J. Laszkiewicz, Z. Puchalski, P. Nawrat, J. Palka, Serum and tissue level of insulin-like growth factor-I (IGF-I) and IGF-I binding proteins as an index of pancreatitis and pancreatic cancer. Int. J. Exp. Pathol. 83, 239-245 (2002)

29. U. Bergmann, H. Funatomi, M. Yokoyama, H.G. Beger, M. Korc, Insulin-like growth factor I overexpression in human pancreatic cancer: evidence for autocrine and paracrine roles. Cancer Res. 55, 2007-2011 (1995)

30. S. Ueda, K. Hatsuse, H. Tsuda, S. Ogata, N. Kawarabayashi, T. Takigawa, T. Einama, D. Morita, K. Fukatsu, Y. Sugiura, O. Matsubara, H. Mochizuki, Potential crosstalk between insulin-like growth factor receptor type 1 and epidermal growth factor receptor in progression and metastasis of pancreatic cancer. Mod. Pathol. 19, 788-796 (2006)

31. H. Werner, I. Bruchim, The insulin-like growth factor-I receptor as an oncogene. Arch. Physiol. Biochem. 115, 58-71 (2009)

32. C. Horndler, R. Gallego, X. Garcia-Albeniz, V. Alonso-Espinaco, V. Alonso, P. Escudero, M. Jimeno, J. Ortego, J. Codony-Servat, C. Fernandez-Martos, A. Calatrava, M. Marin-Aguilera, J. Munoz, S. Castellvi-Bel, A. Castells, M. Rubini, P. Gascon, J. Maurel, Coexpression of matrix metalloproteinase-7 (MMP-7) and phosphorylated insulin growth factor receptor I (pIGF-1R) correlates with poor prognosis in patients with wild-type KRAS treated with cetuximab or panitumumab: a GEMCAD study. Cancer Biol. Ther. 11, 177-83 (2011)

33. M. Guix, M. Granja Nde, I. Meszoely, T.B. Adkins, B.M. Wieman, K.E. Frierson, V. Sanchez, M.E. Sanders, A.M. Grau, I.A. Mayer, G. Pestano, Y. Shyr, S. Muthuswamy, B. Calvo, H. Krontiras, I.E. Krop, M.C. Kelley, C.L. Arteaga, Short preoperative treatment with erlotinib inhibits tumor cell proliferation in hormone receptorpositive breast cancers. J. Clin. Oncol. 26, 897-906 (2008)

34. S. Miyamoto, K. Yano, S. Sugimoto, G. Ishii, T. Hasebe, Y. Endoh, K. Kodama, M. Goya, T. Chiba, A. Ochiai, Matrix metalloproteinase-7 facilitates insulin-like growth factor bioavailability through its proteinase activity on insulin-like growth factor binding protein 3. Cancer Res. 64, 665-671 (2004)

35. A.C. Williams, H. Smartt, A.M. H-Zadeh, M. Macfarlane, C. Paraskeva, T.J. Collard, Insulin-like growth factor binding protein 3 (IGFBP-3) potentiates TRAIL-induced apoptosis of human colorectal carcinoma cells through inhibition of NF-kappaB. Cell Death Differ. 14, 137-145 (2007)

36. F. Ozawa, H. Friess, J. Kleeff, Z.W. Xu, A. Zimmermann, M.S. Sheikh, M.W. Buchler, Effects and expression of TRAIL and its apoptosis-promoting receptors in human pancreatic cancer. Cancer Lett. 163, 71-81 (2001)

37. J. Li, M.W. Saif, Any progress in the management of advanced pancreatic cancer? Highlights from the 45th ASCO annual meeting. Orlando, FL, USA. May 29-June 2, 2009. JOP 10, 361-365 (2009)

38. M.T. Mueller, P.C. Hermann, J. Witthauer, B. Rubio-Viqueira, S.F. Leicht, S. Huber, J.W. Ellwart, M. Mustafa, P. Bartenstein, J.G. D'Haese, M.H. Schoenberg, F. Berger, K.W. Jauch, M. Hidalgo, C. Heeschen, Combined targeted treatment to eliminate tumorigenic cancer stem cells in human pancreatic cancer. Gastroenterology 137, 1102-1113 (2009) 